\title{
Process optimization of ultrasonication-assisted extraction to obtain antioxidant-rich extract from Spirulina platensis.
}

\section{Optimización del proceso de extracción asistida por ultrasonidos para obtener extracto rico en antioxidantes de Spirulina platensis.}

\author{
Smriti Kana Pyne ${ }^{1 *}$, Paramita Bhattacharjee ${ }^{1}$, Prem Prakash Srivastav ${ }^{2}$ \\ ${ }^{1}$ Department of Food Technology and Biochemical Engineering, Jadavpur University, Kolkata- \\ 700032, West Bengal,India \\ 2Department of Agricultural and Food Engineering, Indian Institute of Technology, Kharagpur- \\ 721302, West Bengal, India. \\ *Corresponding author: Department of food Technology and Biochemical Engineering, \\ Jadavpur University, Kolkata; Phone-9476249230; e-mail: smritipyne10@gmail.com
}

\begin{abstract}
In this study highlights on the optimization of extraction process parameters of total phenolic content and antioxidant activity from Spirulina platensis, through ultrasonication (probe) technology. Especially, optimization of ultrasonication parameters was carried out employing Box-Behnken Design (BBD) and response surface methodology (RSM). Alongside the three levels of extraction parameters i.e. solvent volume, extraction time and frequency have been fixed. As responses, the total yield of extract, total phenolic content and DPPH (2,2Diphenyl-1-Picrylhdrazyl) radical scavenging activity $\left(\mathrm{IC}_{50}\right)$ of the extracts were determined. The variability of each response variable was determined by developing multiple linear regressions. The statistical analysis (ANOVA) of developed mathematical models allowed the prediction of the behaviour of the responses, as a function of the variables involved in the process. The optimized extraction conditions were obtained at $58.76 \mathrm{kHz}$ frequency, $10 \mathrm{~mL}$ of solvent volume for $6 \mathrm{~min}$. Simultaneously this extract exhibited the highest content of total phenolic content (30.89 mg GAE/g powder), IC 50 for DPPH activity $(151.27 \mu \mathrm{g} / \mathrm{mL}$ ). The extract exhibited an important antioxidant i.e. caffeic acid, which was quantified as $660.72 \pm 41.05 \mu \mathrm{g} / \mathrm{g}$ of dry algal powder using HPLC. In spite of fact that, this study offers an alternative method for obtaining natural antioxidants from algae for food and pharmaceutical applications.
\end{abstract}


Keywords: Microalgae; Probe sonication extraction; Total phenolic content; Antioxidant activity

\section{RESUMEN}

En este estudio se destaca la optimización de los parámetros del proceso de extracción de contenido fenólico total y actividad antioxidante de Spirulina platensis, mediante tecnología de ultrasonidos (sonda). Especialmente, la optimización de los parámetros de ultrasonidos se llevó a cabo empleando Box-Behnken Design (BBD) y metodología de superficie de respuesta (RSM). Junto con los tres niveles de parámetros de extracción, es decir, el volumen de disolvente, el tiempo de extracción y la frecuencia, se han fijado. Como respuestas, se determinó el rendimiento total de extracto, el contenido fenólico total y la actividad de eliminación de radicales DPPH (2,2-Difenil-1-Picrylhdrazyl) (IC50) de los extractos. La variabilidad de cada variable de respuesta se determinó mediante el desarrollo de regresiones lineales múltiples. El análisis estadístico (ANOVA) de modelos matemáticos desarrollados permitió predecir el comportamiento de las respuestas, en función de las variables involucradas en el proceso. Las condiciones de extracción optimizadas se obtuvieron a una frecuencia de $58,76 \mathrm{kHz}, 10 \mathrm{~mL}$ de volumen de disolvente durante $6 \mathrm{~min}$. Simultáneamente, este extracto exhibió el mayor contenido de contenido fenólico total (30,89 mg GAE / g de polvo), CI50 para la actividad de DPPH $(151,27 \mu \mathrm{g} / \mathrm{ml})$. El extracto exhibió un antioxidante importante, es decir, ácido cafeico, que se cuantificó como 660,72 $\pm 41,05 \mu \mathrm{g} / \mathrm{g}$ de polvo de algas secas mediante HPLC. A pesar de ello, este estudio ofrece un método alternativo para la obtención de antioxidantes naturales a partir de algas para aplicaciones alimentarias y farmacéuticas.

Palabras llave: Microalgas; Sonda de extracción por sonicación; Contenido fenólico total; Actividad antioxidante

\section{PRACTICAL APPLICATIONS}

Spirulina platensis and its extraction products are employed in agriculture, food industry. Spirulina has several pharmacological activities such as antimicrobial (including antiviral and antibacterial) as well as antioxidant effects due to its rich content of protein, polysaccharide, lipid, essential amino and fatty acids. This research object aids as an overview, introducing the basic biochemical composition of this algae and moves to its medical applications. 
Sustainability, Agri, Food and Environmental Research, (ISSN: 0719-3726), 8(X), 2020: http://dx.doi.org/10.7770/safer-VONO-art2252

\section{INTRODUCTION}

Oxidative damage of food is a serious issue of food processing industry that significantly prevented by antioxidants rich substance. Among several algae, Spirulina platensis, blue-green microalgae of the cyanobacteria is widely consumed as a whole food or as a supplement in several countries. It was likewise settled that spirulina is a potential source of high amount of bioactive compounds with functional properties such as antioxidants, phenolic compounds i.e. salicylic, trans-cinnamic, synaptic, chlorogenic, caffeic acid and polyunsaturated fatty acids (Goiris et al. 2012; Naczk et al. 2004; Saha et al. 2016).

Extraction of bioactive elements from microalgae species prompt to a gainfull impact on food processing and preservation industries, that was successfully conducted by several researchers (Mata et al. 2010; Hafting et al. 2012; Shalaby et al. 2013). Strikingly it was seen that, caffeic acid (hydroxyl cinnamic acid consists of both phenolic and acrylic groups) is one of the most important antioxidants used as biopharmaceutical molecule. Prior reports confirm that, the various extraction factors such as nature of extraction solvent, frequency and extraction time would give an impact on the rate of extraction/extraction efficiency and amount of extracted antioxidative biomolecules (Herrero et al. 2006). Simulteniously several conventional methods such as maceration and Soxhlet extraction has been conducted to obtain algal extract from biomass (Tabaraki et al. 2011; Ballard et al. 2009; Liyana-Pathirana et al. 2005). Albeit these conventional extraction methods have additional demerits such as large amount of solvent usage, lengthy extraction time and lower extracted constituents (Balboa et al. 2013).

For that reason, the above extraction methods are not applicable in food and pharmaceutical industries. Hence, the alternative extraction methodologies like ultrasoundassisted extraction (UAE), microwave-assisted extraction (MAE), and supercritical fluid extraction (SFE) are employed to overcome these drawbacks (Wang et al. 2006). Particularlly UAE is an inexpensive, emerging and efficient technique that accelerates heat and mass transfer during extraction. UAE reduces extraction time, increases extraction yield, rate of extraction and antioxidant properties of extracts as compared to conventional methods (Chemat et al. 2011; Aybastier et al. 2013). One of the generally significant and ubiquitously expressed that, it is an attractive alternative green technology.

The present study principally focuses on the optimization of the probe sonication extraction parameters such as solvent volume, extraction time and frequency using response surface methodology based on the exact combination of phytochemical properties (total phenolic content and antioxidant activity) of the extracts. This study reports the extraction of caffeic acid by UAE as an antioxidant from Spirulina platensis. As a matter of fact especially this work endeavours to acquire a harmless 'green' extract from algae for favourable end-use of the same as a nutraceutical food supplement. 


\section{MATERIALS AND METHODS}

Sample Materials: The microorganism Spirulina platensis var. lonor used in this study was procured from Antenna Green Trust, Madurai, Tamil Nadu, India. Afterward, the samples were preserved under dry and dark conditions in amber coloured sealed plastic container until use.

Chemical Reagents: Ethanol 99.9\% (ChemSoln), Gallic acid (Merck, Mumbai, India), Sodium carbonate anhydrous (Fisher Scientific), Sodium nitrite (R\&M Chemicals), Aluminium chloride (System), Folin \& Ciocateu's Phenol Reagent (ChemSoln), Quercetin (Sigma-Aldrich), 2,2-Diphenyl-1-Picrylhdrazyl (DPPH) (Riendemann Schidt) and Sodium hydroxide (Riendemann Schidt) were of analytical grade.

Preparation of samples for UAE: Initially the algal biomass was placed in a freeze dryer for lyophilization (Eyela, FDU 1200, Tokyo, Japan) and stored in dry and dark conditions in amber coloured airtight container prior to UAE. Furthermore the lyophilized algal powder was sieved in a sieve shaker (Chatterjee et al. 2013). The algal powder samples with mean particle diameter $\left(d_{p}\right)$ of $1 \mathrm{~mm}$ were selected for extractions.

\section{Optimization of UAE parameters to obtain antioxidant-rich extract from} Spirulina platensis: An ultrasonic probe processor (UP50H, Hielscher Ultrasound Technology, Teltow, Germany) with a $2 \mathrm{~mm}$ titanium microprobe tip operating at the different frequency level of $20-100 \mathrm{kHz}$ and $50 \mathrm{~W}$ input power was employed for treatments of extraction media. All round the entire extraction procedure was performed at a fixed duty cycle (ultrasonic pulse cycle ratio) of 1.0. A few Preliminary trials conducted with three different extraction solvents (ethanol, distilled water and hexane), revealed that ethanol gave the maximum total yield of the extract. This polar solvent remarkable has been known as a suitable solvent for recovering polyphenols (Azmir et al. 2013). Emphatically UAE was carried out with $1 \mathrm{~g}$ of lyophilized algal samples at different frequency, solvent volume, and sonication times according to the experimental design. In the present context, the Box-Behnken design (BBD), a class of rotatable or nearly rotatable second-order designs based on three-level incomplete factorial design with three independent variables viz. solvent volume, frequency and time and three dependent variables viz. total yield percentage, total phenolic content and IC $C_{50}$ values of DPPH radical scavenging activity of dried algal extract was used for scheming the experiment (Ferreira et al. 2007). Therefore preliminary trials suggested that significant yields of algal extract with appreciable phytochemical properties were obtained within a sonication time of 2$10 \mathrm{~min}$, solvent volume in a range of 10 to $25 \mathrm{~mL}$ and frequency of 20 to $100 \mathrm{kHz}$. Based on the preliminary trials, the extraction time $(2,6,10 \mathrm{~min})$ solvent volume $(10,30,50 \mathrm{~mL})$ and 
frequency $(20,60,100 \mathrm{kHz})$ were varied at three levels respectively. A total of 13 experiments were performed and four additional runs at the star points were carried out in a randomized run order (Danh et al. 2012).

After that all algal extracts were then centrifuged for $15 \mathrm{~min}$ at $13500 \mathrm{~g}$ (SIGMA Laborzentrifugen 2-16 PK refrigerated centrifuge) to separate the liquid phase. For the most part of liquid supernatant was collected and dried using a rotary evaporator (Supervac-R/180; Superfit Continental Pvt. Ltd., Mumbai, India) under reduced pressure of $50 \mathrm{mbar} \mathrm{Hg}$ at vacuum temperature of $40-50{ }^{\circ} \mathrm{C}$ and finally dried by purging a gentle stream of nitrogen and their yields were determined gravimetrically [yield $(\%)=$ "mass of concentrated extract " /"Initial mass of microalgae"*100]. Fundamentally the extracts were kept in nitrogen flushed amber coloured screw capped glass vials at $4^{\circ} \mathrm{C}$ for the subsequent analyses.

Evaluation of phytochemical properties of UAE algal extracts:Determination of total phenol content and DPPH radical scavenging activity of the UAE extract: Total phenolic content and free radical scavenging activity (DPPH) of the algal extracts were estimated in accordance with the method described by Singleton and Rossi (1965) and Ghosh et al. (2013) respectively.

\section{Liquid chromatography-mass spectroscopy (LC-MS) analysis of the UAE} extract obtained under optimized extraction conditions:The extract obtained under optimized UAE conditions was coded as UAE best. The sample was subjected to liquid chromatography-tandem mass spectrometry (LC-MS/MS) for the identification of compounds. The UAE extract was suspended in $0.1 \%$ formic acid, injected and captured in a $\mathrm{C}_{18}$ trapping cartridge. The trapped bioactive compounds were eluted onto a C18 analytical column. The elution gradient consisted of mobile phase $A$ (water and $0.1 \%$ formic acid) and mobile phase $B$ (methanol and $0.1 \%$ formic acid). The mass spectrum was obtained in the negative ESI ionisation mode over an $\mathrm{m} / \mathrm{z}$ range of 100-1200. The temperature and voltage of the curved desolvation line were set to $230^{\circ} \mathrm{C}$; and $+85 \mathrm{~V}$, respectively. The probe voltage and nitrogen nebulizer gas flow were set at $+4.5 \mathrm{kV}$ and $4.5 \mathrm{l} / \mathrm{min}$, respectively.

\section{Quantification of caffeic acid in the UAE extract obtained under optimized} extraction conditions: UAE best was subjected to HPLC for quantification of caffeic acid (Wang et al. 2004). UAEbest was filtered through a $0.22 \mu \mathrm{m}$ polytetrafluorethylene syringe filter prior to HPLC injection at an injection volume of $20 \mu \mathrm{L}$ into an Agilent ZORBAX SB C-18 column $(150 \times 4.6$ mm, $5 \mu \mathrm{m}) 1300$ series HPLC (Agilent Technologies Inc., Alpharetta, GA, USA). The flow rate of the mobile phase was set at $0.8 \mathrm{~mL} / \mathrm{min}$ with a gradient elution of water-acetic acid $(95: 5, \mathrm{v} / \mathrm{v})(\mathrm{A})$ and methanol-acetonitrile-acetic acid (95:5:1, v/v/v) (B), starting from 
Sustainability, Agri, Food and Environmental Research, (ISSN: 0719-3726), 8(X), 2020:

http://dx.doi.org/10.7770/safer-VONO-art2252

$0 \%$ to $40 \% \mathrm{~B}$ in $10 \mathrm{~min}, 40 \%-100 \% \mathrm{~B}$ in $10 \mathrm{~min}, 100 \% \mathrm{~B}$ in $5 \mathrm{~min}$, and $100 \%-5 \% \mathrm{~B}$ in $5 \mathrm{~min}$. The authentic standard of caffeic acid was solubilized in mobile phase $B$ and concentration prepared at $100,80,60,40,20 \mathrm{mg} / \mathrm{mL}$ in order to plot standard curve. Each solution was injected three times and the mean peak areas were considered for the preparation of standard curve and the results were expressed in $\mu \mathrm{g} / \mathrm{g}$ of algal powder.

Analysis of amino acids profile of UAE $\mathrm{E}_{\text {best: }}$ The nutritional quality of a protein is mostly determined by the proportion, content and availability of its amino acids (WHO. 2007). In order to understand the nature of toxic peptides, the amino acid composition of UAEbest was determined (Gupta et al. 2013). The UAEbest filtrate was subjected to quantitative HPLC analysis for the determination of amino acids profile. A Licrosper 100 RP 18 column ( $4 \mathrm{~mm} \times 125 \mathrm{~mL})$ was used to separate the compound. The mobile phase solution consisted of methanol and mercaptoethanol solvents.The fluorescence Shimadzu RF-138 detector was used and the excitation wavelength and an emission wavelength were $360 \mathrm{~nm}$ and $460 \mathrm{~nm}$ respectively.

Statistical analysis: The results of all experiments were conducted in triplicate and data are reported as mean \pm SD of three independent experimental runs. Statistical analysis of the data was conducted by one-way analysis of variance (ANOVA), response surface analysis (RSM) and regression modelling. The significance differences between variables were tested by ANOVA and significant differences between means were calculated with post hoc Duncan's test at $5 \%$ level of significance. In the present study, STATISTICA 8.0 (Statsoft, Oklahoma, USA) and Design Expert 7.0 (Stat-Ease Inc., Minneapolis, MN, USA) softwares were used to assess the experimental results.

\section{RESULTS AND DISCUSSION}

Total yield of Spirulina extracts and its corresponding total phenol content

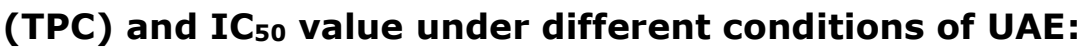

Effect of UAE time on total yield and its corresponding TPC and IC 50 value of UAE extract: The extraction time is significant to deduce the energy and cost of the extraction process.UAE time has insignificant effect on total phenol content $(p=0.11)$ but has a significant effect on the extract yield $(p=0.01)$ and $\mathrm{IC}_{50}$ value $(p=0.001)$. A significant interaction between extraction time and solvent volume on TPC $(p=0.01)$ and IC 50 value $(p=0.007)$ was obtained. The Figure 1 showed that the yield increased quickly with increasing time. The yield of extract during 2 to $6 \mathrm{~min}$ interval and at $10 \mathrm{~min}$ was low and highest respectively. The maximum concentration of phenolic compounds was achieved at extraction time of 6 mins. The values of phenolic content after 6 mins of extraction time were decreased gradually and insignificantly $(p<0.05)$. An excessive sonication time causes heating of the extraction solvent, results into 
the degradation of extracted bioactive compounds (Pan et al. 2012). It can also be determined that the DPPH in term of antioxidant capacity decreased after reaching a maximum value at 10 mins because the prolonged extraction time might be increased the probabilities of phenolic compounds.

Effect of UAE frequencies on total yield and its corresponding TPC and IC 50 value of algal extract: The Figure 1, 2 and 3 represented that the extract yield, TPC and IC 50 were significantly affected by UAE frequencies. The yield of extract increased as frequency was increased. The $\mathrm{IC}_{50}$ value was affected by independent parameters viz., frequency and time. UAE frequency has insignificant effect on total phenol content $(p=0.62)$ but has a significant effect on the extract yield $(p=0.007)$ and IC $_{50}$ value $(p=0.000)$. It showed that with an increase in frequency from 20 to $60 \mathrm{kHz}$, the yield increased, but; beyond this the yield decreased. A significant interaction between solvent volume and frequency on TPC ( $p=0.02)$ was obtained. At frequency up to $60 \mathrm{kHz}$, with increase in solvent volume, TPC decreased from 26.97 to 23.8 $\mathrm{mg} \mathrm{GAE} / \mathrm{g}$ algal powder, whereas; at higher frequency, TPC remained constant at $26.97 \mathrm{mg}$ $\mathrm{GAE} / \mathrm{g}$ algal powder.

Effect of extraction solvent volume on total yield and its corresponding TPC and IC 50 value of algal extract: The enrichment of the extraction yield of polyphenols can occur when a higher solvent volume can dissolve ingredients more effectively ( $\mathrm{Li}$ et al. 2005). In such context, different solvent volume was tested in order to express the effect of solvent concentration in extracting the natural antioxidants. Solvent volume has insignificant effect on extract yield $(p=0.75)$ and IC 50 value $(p=0.86)$, however; has a significant effect on TPC ( $p$ $=0.00$ ) due to sonothermal degradation of bioactive compounds (Rawson et al. 2011). A significant interaction between solvent volume and extraction time on TPC $(p=0.01)$ and IC 50 value ( $p=0.007$ ) was obtained. The effect of ethanol solvent volume on antioxidant capacities and phenolic contents of crude extract is shown in Figure 2 and 3. It was observed that at the lower time, with an increase in solvent volume, IC $_{50}$ value decreased from 142.26 to 133.57 $\mathrm{\mu g} / \mathrm{mL}$, whereas; with an increase in both solvent volume and time, there was maximum $\mathrm{IC}_{50}$ $184.58 \mu \mathrm{g} / \mathrm{mL}$ (Table 2).

\section{Optimization of UAE parameters for maximizing total yield, TPC and IC 50 value of the extract:}

Generation of response curves: The effects of extraction time, solvent volume and frequency on the total yield percentage, TPC and IC 50 values of extracts are shown in Figures 1 (A-C) respectively. Regression modeling was used for the characterization of the response surfaces. 
Regression Modelling: Regression modelling was conducted by generating second order polynomial equations for response as a function of extraction time and frequency. Based on a designed set of experimental data using RSM, the model parameters of Eqn. 1 were statistically determined. In order to be evaluated in RSM, the real value of independent variables must be transformed into the coded variables. In this study, three independent variables were used and $Y$ was set as response variables (total yield percentage, TPC and IC 50 of dried algal extract. A second-order polynomial regression model for the dependent variable was established to fit the experimental data for each response as per the following equation:

$Y=\beta_{0}+\Sigma \beta_{i} X_{i}+\sum \beta_{i i} X_{i}^{2}+\Sigma \beta_{i j} X_{i} X j$

Where, $Y$ represents the experimental responses [total yield of extract (Eqn. 2), TPC value of extract (Eqn. 3) and IC50 value of extract (Eqn. 4) $; X_{\mathrm{i}}, X_{\mathrm{j}}$ are two independent variables in coded forms; $\beta_{\mathrm{o}}, \beta_{\mathrm{i}}, \beta_{\mathrm{ii}}$ and $\beta_{\mathrm{ij}}$ are constants and regression coefficients of the model. The expanded model includes linear, quadratic, and cross-product terms as shown below (with intercept):

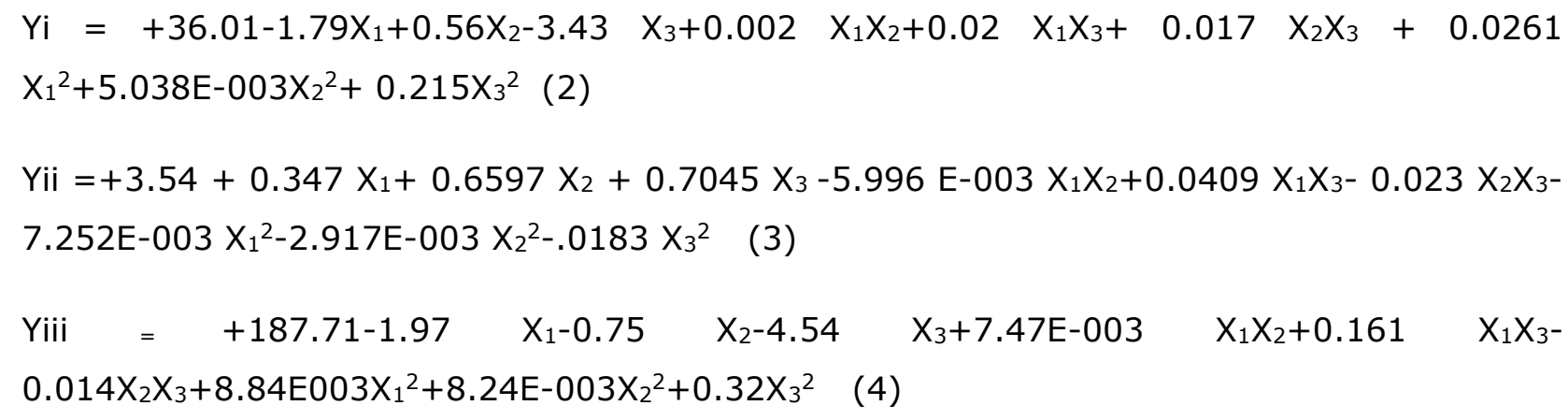

Yiii $=+187.71-1.97 \quad X_{1}-0.75 \quad X_{2}-4.54 \quad X_{3}+7.47 E-003 \quad X_{1} X_{2}+0.161 \quad X_{1} X_{3}-$ $0.014 \mathrm{X}_{2} \mathrm{X}_{3}+8.84 \mathrm{E} 003 \mathrm{X}_{1}^{2}+8.24 \mathrm{E}-003 \mathrm{X}_{2}^{2}+0.32 \mathrm{X}_{3}^{2}$

Where, $X_{1}, X_{2}$ and $X_{3}$ are extraction solvent volume, frequency and time respectively. The above equations $(2,3$, and 4$)$ explain the effects of $X_{1}, X_{2}$ and $X_{3}$ on the response $Y i$ (total yield of extract), Yii (TPC) and Yiii (IC 50 of extract). The effects of the above parameters and their interactions were evaluated. The ANOVA table (Table 1 ) was used to study the effect of each independent variable constructing a model that maximized extraction yield, total phenolic content and antioxidant activity of Spirulina $s p$. This analysis also gave values of the model term tested for adequacy and fitness. The statistical analysis of F-value and probability value $(p)$ indicated that the model was actually significant. The fit of the model was checked by the coefficient of determination $\left(R^{2}\right)$ which was $0.99,0.93$ and 0.93 and the $p$-value $(>0.05)$ for the lack of fit analysis were $0.11,0.08$ and 0.07 for yield, TPC and IC 50 respectively. The values of lack of fit were not significant, indicating that the model equations were adequate for predicting the yield percentage, TPC and IC 50 under any combinations of variable factors. 
Sustainability, Agri, Food and Environmental Research, (ISSN: 0719-3726), 8(X), 2020 :

http://dx.doi.org/10.7770/safer-VONO-art2252

Table 1.

Analysis of variance (ANOVA) for fitted response surface quadratic model of total yield of extract, total phenolic content (TPC) and DPPH radical scavenging activity (IC 50 )

Total Yield of extract

\begin{tabular}{lllllll}
\hline Source & Sum of squares & Df & Mean square & F-value & Probability $(\mathrm{P})>\mathrm{F}$ & \\
Model & 1102.33 & 9 & 122.47 & 233.81 & 0.0001 & Significant \\
Lack of fit & 2.73 & 3 & 0.91 & 3.91 & 0.1106 & Non-significant \\
Pure error & 0.93 & 4 & 0.23 & & & \\
Corrected total & 1105.89 & 16 & & & \\
$\mathrm{R}^{2}$ & 0.9967 & & & & \\
$\mathrm{R}^{2}$ adj & 0.9924 & & & & \\
\hline
\end{tabular}

Total phenolic content (TPC)

\begin{tabular}{|c|c|c|c|c|c|c|}
\hline Source & Sum of squares & $\mathrm{Df}$ & Mean square & F-value & Probability $(\mathrm{P})>\mathrm{F}$ & \\
\hline Model & 470.63 & 9 & 52.29 & 208.8 & 0.0001 & Significant \\
\hline Lack of fit & 1.37 & 3 & 0.46 & 4.80 & 0.0818 & $\begin{array}{l}\text { Non- } \\
\text { significant }\end{array}$ \\
\hline Pure error & 0.38 & 4 & 0.095 & & & \\
\hline Corrected total & 472.38 & 16 & & & & \\
\hline $\mathrm{R}^{2}$ & 0.9372 & & & & & \\
\hline$R^{2}$ adj & 0.8565 & & & & & \\
\hline \multicolumn{7}{|c|}{$\mathrm{IC}_{50}$} \\
\hline Source & Sum of squares & $\mathrm{Df}$ & Mean square & F-value & Probability $(P)>F$ & \\
\hline Model & 4977.23 & 9 & 553.03 & 11.75 & 0.0019 & Significant \\
\hline Lack of fit & 259.80 & 3 & 86.60 & 4.98 & 0.0776 & $\begin{array}{l}\text { Non- } \\
\text { significant }\end{array}$ \\
\hline Pure error & 69.62 & 4 & 17.41 & & & \\
\hline Corrected total & 5306.65 & 16 & & & & \\
\hline $\mathrm{R}^{2}$ & 0.9379 & & & & & \\
\hline$R^{2}$ adj & 0.8581 & & & & & \\
\hline
\end{tabular}


The significance of each variable was determined by its respective $p$-value and F-value at a specified level of confidence. In fact, the smaller $p$-value is more important with respect to coefficient of the response variable. The $p$-value for each response was greater than 0.5 , which suggests that the effect ofindependent variables on the response model was not statistically significant at $95 \%$ confidence level.

Table 2.

Experimental design of three-level independent variables and its corresponding responses. All data are the mean \pm SD of three replicates. SD followed by different subscripts in the same column differs significantly $(p \leq 0.05)$

\begin{tabular}{|c|c|c|c|c|c|c|}
\hline Run & $\begin{array}{c}\text { A: } \\
\text { Solvent } \\
\text { volume } \\
(\mathrm{mL})\end{array}$ & $\begin{array}{c}\text { B: } \\
\text { Frequency } \\
(\mathrm{kHz})\end{array}$ & $\begin{array}{c}\text { C: } \\
\text { Time } \\
(\min )\end{array}$ & $\begin{array}{c}\text { Yield \%of algal } \\
\text { extract }\end{array}$ & $\begin{array}{l}\text { Total phenolic } \\
\text { content (mg } \\
\text { gallic acid } \\
\text { equivalent/g dry } \\
\text { algae) }\end{array}$ & $\begin{array}{l}\text { IC50 value of } \\
\text { DPPH radical } \\
\text { scavenging } \\
\text { activity }(\mu \mathrm{g} / \mathrm{ml})\end{array}$ \\
\hline 1 & 10 & 20 & 6 & $20.86 \pm 0.006$ & $20.16 \pm 0.22^{i}$ & $149.22 \pm 0.04^{\mathrm{h}}$ \\
\hline 2 & 50 & 20 & 6 & $19.72 \pm 0.03^{j}$ & $21.35 \pm 0.06^{h}$ & $130.78 \pm 0.09$ \\
\hline 3 & 10 & 100 & 6 & $27.17 \pm 0.05^{g}$ & $29.75 \pm 0.09^{b}$ & $176.14 \pm 0.05^{d}$ \\
\hline 4 & 50 & 100 & 6 & $28.44 \pm 0.02^{f}$ & $11.75 \pm 0.03^{\prime}$ & $181.63 \pm 0.03^{b}$ \\
\hline 5 & 10 & 60 & 2 & $34.02 \pm 0.13^{c}$ & $30.89 \pm 0.07^{a}$ & $150.98 \pm 0.06^{g}$ \\
\hline 6 & 50 & 60 & 2 & $32.2 \pm 0.05^{d}$ & $16.59 \pm 0.07^{k}$ & $129.87 \pm 0.0^{\mathrm{m}}$ \\
\hline 7 & 10 & 60 & 10 & $37.17 \pm 0.07^{b}$ & $27.11 \pm 0.04^{\mathrm{e}}$ & $147.02 \pm 0.11^{i}$ \\
\hline 8 & 50 & 60 & 10 & $41.91 \pm 0.05^{a}$ & $25.92 \pm 0.15^{f}$ & $177.67 \pm 0.02^{c}$ \\
\hline 9 & 30 & 20 & 2 & $11.72 \pm 0.07^{\mathrm{m}}$ & $19.19 \pm 0.04^{j}$ & $132.87 \pm 0.06^{k}$ \\
\hline 10 & 30 & 100 & 2 & $16.35 \pm 0.11^{k}$ & $25.12 \pm 0.03^{g}$ & $158.56 \pm 0.07^{f}$ \\
\hline 11 & 30 & 20 & 10 & $14.22 \pm 0.03^{\prime}$ & $29.01 \pm 0.06^{c}$ & $168.12 \pm 0.02^{\mathrm{e}}$ \\
\hline 12 & 30 & 100 & 10 & $29.81 \pm 0.10^{e}$ & $20.12 \pm 0.02^{i}$ & $184.58 \pm 0.07^{a}$ \\
\hline 13 & 30 & 60 & 6 & $22.43 \pm 0.08^{\mathrm{h}}$ & $28.46 \pm 0.02^{d}$ & $140.12 \pm 0.03^{j}$ \\
\hline
\end{tabular}



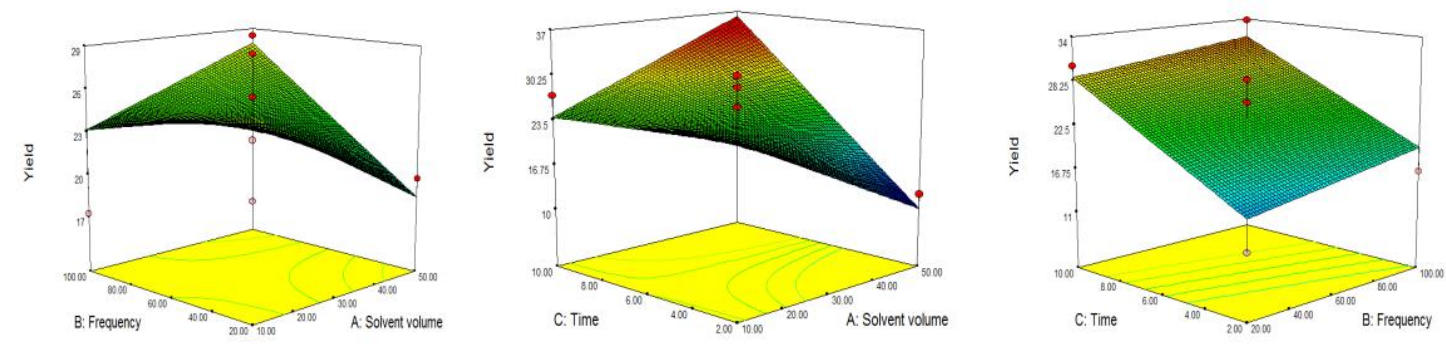

Figure 1: Response surface plot for Total yield of extract with respect to frequency $(\mathrm{kHz})$, solvent volume $(\mathrm{mL})$ and extraction time $(\mathrm{min})$ and their mutual interactions
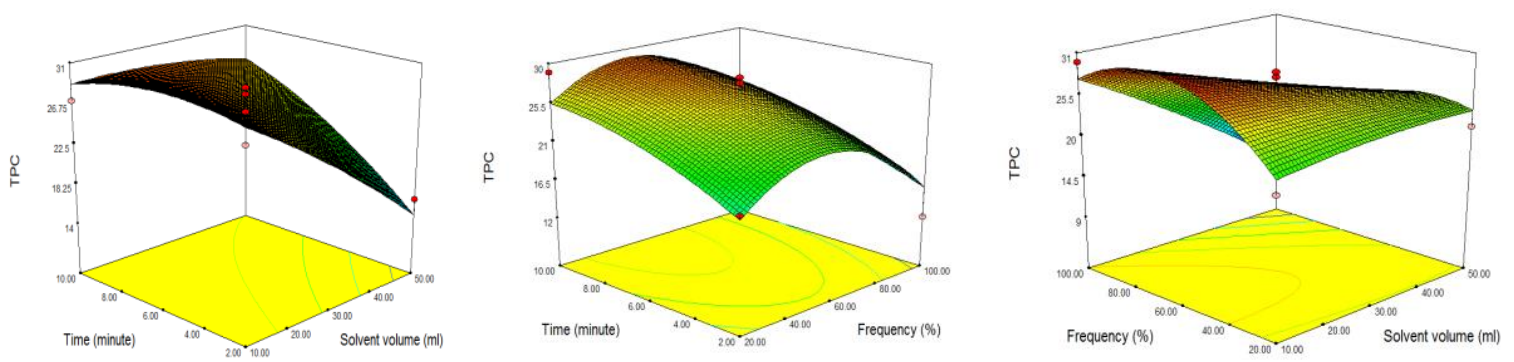

Figure 2: Response surface plot forTotal phenolic content (TPC) with respect to solvent volume $(\mathrm{mL})$, extraction time $(\mathrm{min})$ and frequency $(\mathrm{kHz})$ and their mutual interactions
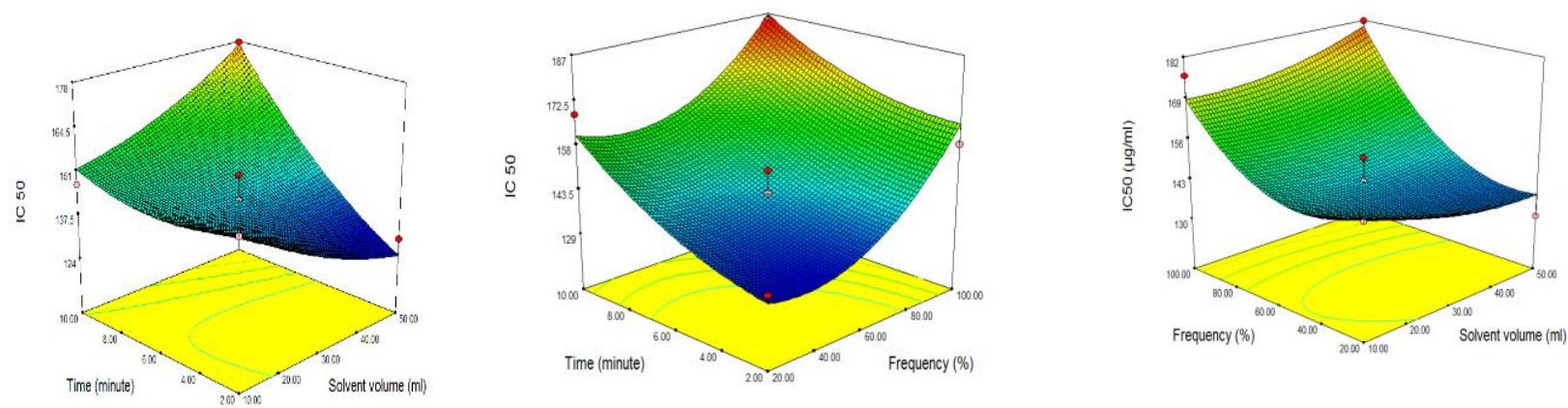

Figure 3: Response surface plot for DPPH scavenging activity $\left(\mathrm{IC}_{50}\right)$ with respect to solvent volume $(\mathrm{mL})$, extraction time $(\mathrm{mL})$ and frequency $(\mathrm{kHz})$ and their mutual interactions on DPPH scavenging activity (IC50)

Optimal Processing Conditions: The optimal values of $\mathrm{X}_{1}, \mathrm{X}_{2}$ and $\mathrm{X}_{3}$ were determined to obtain the optimal processing conditions for total yield, TPC and IC ${ }_{50}$ of probe sonicated extract from S. platensis. The first partial derivatives of the regression equation were exhibited with respect to $X_{1}, X_{2}$, and $X_{3}$ and set to zero by putting the second-order regression equation in 
matrix form (Chakraborty et al. 2017). Thus the obtained points are known as the stationary point: $X_{1 S}=10 \mathrm{~mL}, X_{2 S}=58.76 \mathrm{kHz}, X_{3 S}=6 \mathrm{~min}$. Under these conditions the maximum predicted yield, TPC and IC 50 of the extractwere about $33.94 \%, 30.89 \mathrm{mg} \mathrm{GAE} / \mathrm{g}$ of algal powder and $151.27 \mu \mathrm{g} / \mathrm{mL}$ respectively; whereas, the actual experimental values obtained were $34.02 \%, 29.52 \mathrm{mg} \mathrm{GAE} / \mathrm{g}$ of powder and $150.98 \mu \mathrm{g} / \mathrm{mL}$ respectively; suggesting a close fit model.

Characterizing the Response Surfaces: The response curve was characterized by determining whether the stationary point obtained in the curve is a point of maximum response, minimum response, or a saddle point. For this purpose, the regression equation was transformed into the canonical forms and the eigen values in accordance with the method described by Chatterjee et al. (2013). Since the eigen values for extract yield $(0.289266$, $0.026627,0.0047781)$ and IC $_{50}$ value $(0.320469,0.008844,0.00824)$ were positive, $X_{s}$ was a point of minima. The eigen values obtained in case of TPC were $-0.00044,-0.00325$, 0.051156 , since; the eigen values obtained were negative, the optimum point obtained was a point of maximum response.This extraction condition was considered as the optimized condition as the extract exhibited the highest yield percentage, total phenol content and antioxidant activity.

Yield of caffeic acid in UAE best: From the above discussion, it was found that the algal extract obtained at $60 \mathrm{kHz}$ in $10 \mathrm{~mL}$ of solvent for 6 min has the best combination of phenolic content and antioxidant/ DPPH radical scavenging activity. The amount of caffeic acid obtained in this extraction condition was $69.32 \mu \mathrm{g} / \mathrm{g}$ dry algae and identified as one of the active antioxidant (Gulcin, 2006).

Phenolic acids profile of the UAEbest: All food groups have phenolic acid abundantly found in vegetables, and fruits even in oilseeds and legumes. Several phenolic acids possess high antioxidant activity due to uptake hydroxyl radical, singlet oxygen, peroxyl radical, superoxide anion etc. We have visualised phenolic acid exists as hydroxyl cinnamic acids which include caffeic acid (CA), ferulic acid (FA), chlorogenic acid (CGA), and sinapic acids (SA) and hydroxyl benzoic acids which include gallic acid (GA), salicylic acid (SA) or occur as conjugated forms. However, these compounds are more energetic molecules than carbohydrate and protein. Simultaneously, they can be serve as key regulator of several industries such as biofuels, food, etc. The phenolic components of UAEbest have been presented in Table 3. From Figure $4 \mathrm{a}$ and $4 \mathrm{~b}$ it was found that ferulic acid, caffeic acid, trans caffeic acid hexoside, chlorogenic acid are the extracted components, all of which reportedly have nutraceutical properties (Elagbar et al. 2016). 
Sustainability, Agri, Food and Environmental Research, (ISSN: 0719-3726), 8(X), 2020 :

http://dx.doi.org/10.7770/safer-VONO-art2252

18EAUG22 Sm (Mn, 2x1); Sm (Mn, 2x1)

1: MS2 ES+

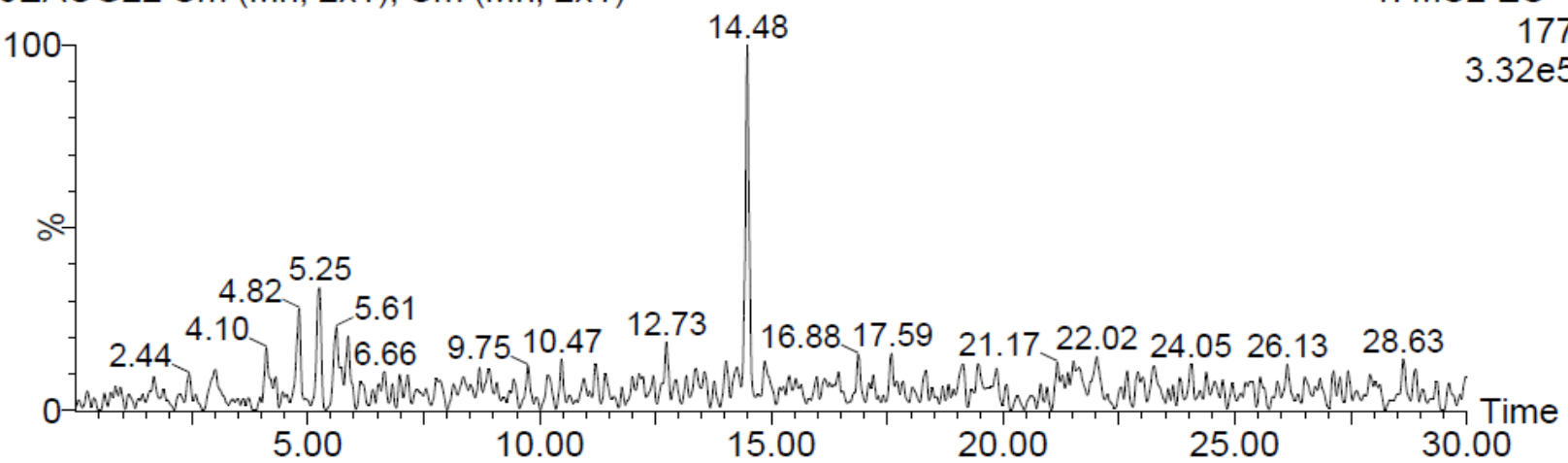

Figure 4a: Total chromatogram of UAEbestextract.

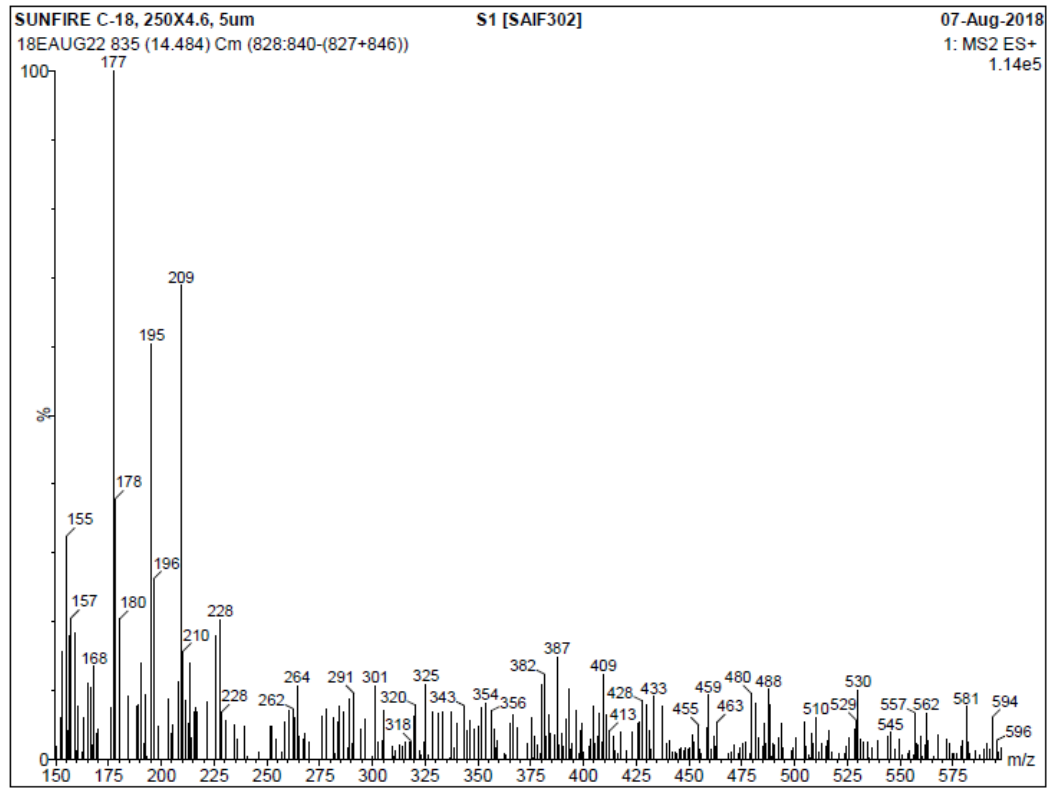

Figure 4b: LC-MS chromatogram of Spirulina platensisof UAEbestextract

Table 3.

Retention times, MS and $\mathrm{MS}^{2}$ values of the major bioactive constituents present in SC$\mathrm{CO}_{2}$ extract of Spirulina platensis identified by LC-MS

Retention time (RT) Molecular ion peak $(\mathrm{M}-\mathrm{H})^{-} \quad \mathrm{MS}^{2}$ fragment ions $\quad$ Tentative Compounds identified
intensity

\begin{tabular}{lccc}
\hline 8.62 & 341 & 161,179 & Trans caffeic acid hexoside \\
9.52 & 195 & 178,179 & Caffeic acid \\
14.48 & 195 & $177,178,195$ & Ferulic acid \\
21.16 & 340 & 179,340 & Caffeic acid derivative
\end{tabular}


Detection of toxic peptides through amino acids profiling of $U A E_{b e s t}$ : The result regarding amino acid profile of spirulina extract from the HPLC analysis is given in Table 4. It is clear from the results that spirulina UAE extract is good source of leucine, valine, isoleucine, lysine, glutamic acid, aspartic acid, alanine, proline and arginine. The results for essential amino acids in UAEbestexhibited; leucine in large proportion $(0.89 \mathrm{~g} / 100 \mathrm{~g}$ algal powder) followed by valine $(0.27 \mathrm{~g} / 100 \mathrm{~g}$ algal powder). It is accepted that cereals are main source of essential amino acids but lysine and tryptophan are present in low amount. Besides that, these amino acids are present in high concentration in spirulina extract that can be a choice for supplementation in cereals and cereals based diets.

\section{Table 4.}

Essential and non-essential amino acids profile of UAE extract

\begin{tabular}{cc}
\hline Amino Acids & Amount $(\mathrm{g} / 100 \mathrm{~g}$ dry algae $)$ \\
\hline Phenylalanine & 0.31 \\
Methionine & 0.63 \\
Threonine & 0.08 \\
Valine & 0.27 \\
Isoleucine & 0.11 \\
Leucine & 0.89 \\
Lysine & 0.36 \\
Histidine & 0.56 \\
Tryptophan & 0.42 \\
Alanine & 1.09 \\
Arginine & 1.01 \\
Aspartic acid & 1.64 \\
Glutamic acid & 0.054 \\
Glycine & 0.61 \\
Proline & 0.98 \\
Cysteine & $<0.05$ \\
Tyrosine & 1.23 \\
\hline
\end{tabular}

As conclusions, the solvent volume, ultrasound frequency and extraction time had significantly influenced the yield, total phenolic content and antioxidant activity of theextract. 
It is accepted that the extraction yield was $33.94 \%$ and IC $_{50}$ of DPPH radical scavenging activitywas $151.27 \mu \mathrm{g} / \mathrm{mLw}$ ith caffeic acid content of $69.32 \mu \mathrm{g} / \mathrm{g}$ dry algae under the optimalconditions for-UAEbest. Consequently, we envisage that caffeic acid is a safe and antioxidant-rich fraction obtained from Spirulina platensis by UAE green technology would have promising application in food and pharmaceutical industries. Additionally, there is considerable future scope for research in developing various types of food products with extract of microalgae.

\section{ACKNOWLEDGEMENTS}

Authors are acknowledged to the University Grants Commission, India for proving financial help.

\section{REFERENCES}

Aybastier, O., Işık, E., Şahin, S. and Demir, C. 2013. Optimization of ultrasonic-assisted extraction of antioxidant compounds from blackberry leaves using responsesurface methodology. Ind. Crop. Prod. 44: 558-565.

Azmir, J., Zaidul, I.S.M., Rahman, M.M, Sharif, K.M, Mohamed, A., Sahena, F. and Omar, A.K.M. 2013. Techniques for extraction of bioactive compounds from plant materials: A review. Journal of Food Engineering; 117(4): 426-436.

Ballard, T.S., Mallikarjunan, P., Zhou, K. and O'Keefe, S.F. 2009. Optimizing the extraction of phenolic antioxidantsfrom peanut skins using response surface methodology. Journal of Agricultural and Food Chemistry; 57(8): 3064-3072.

Balboa, E.M., Conde, E., Moure, A., Falqué, E. and Domínguez, H. 2013. In vitro antioxidant properties of crude extracts and compounds from brown algae. Food chemistry; 138(23): $1764-1785$.

Chakraborty, S. and Bhattacharjee, P. 2017. Supercritical carbon dioxide extraction of melatonin from Brassica campestris: in vitro antioxidant, hypocholesterolemic and hypoglycaemic activities of the extracts. International Journal of Pharmaceutical Sciences and Research; 8(6), 2486-2495.

Chatterjee, D. and Bhattacharjee, P. 2013. Supercritical carbon dioxide extraction of eugenol from clove buds. Food and Bioprocess Technology; 6: 2587- 2599. 
Sustainability, Agri, Food and Environmental Research, (ISSN: 0719-3726), 8(X), 2020 :

http://dx.doi.org/10.7770/safer-VONO-art2252

Chemat, F., Huma, Z. and Khan, M.K. 2011. Applications of ultrasound in food technology: Processing, preservation and extraction. Ultrason. Sonochem.; 18: 813-835.

Danh, L.T., Triet, N.D.A., Han, L.T.N., Zhao, J., Mammucari, R. and Foster, N. 2012. Antioxidant activity, yield and chemical composition of lavender essential oil extracted by supercritical $\mathrm{CO}_{2}$. J. Supercrit. Fluids; 70: 27-34.

Elagbar, Z. A., Naik, R. R., Shakya, A.K. and Bardaweel, S. K. 2016. Fatty acids analysis, antioxidant and biological activity of fixed oil of Annona muricata L. seeds. Journal of Chemistry.

Ferreira, S. C., Bruns, R. E., Ferreira, H. S., Matos, G. D., David, J.M., Brandao, G. C. and Dos Santos, W. N. L. 2007. Box-Behnken design: an alternative for the optimization of analytical methods. Analytica chimica acta; 597(2): 179-186.

Gulçin, İ. 2006. Antioxidant activity of caffeic acid (3, 4-dihydroxycinnamic acid). Toxicology; 217(2-3): 213-220.

Ghosh, S., Chatterjee, D., Das, S. and Bhattacharjee, P. 2013. Supercritical carbon dioxide extraction of eugenol-rich fraction from Ocimum sanctum Linn and a comparative evaluation with other extraction techniques: Process optimization and phytochemical characterization. Industrial Crops and Products; 47: 78- 85.

Goiris ,K., Muylaert, K., Fraeye, I., Foubert, I., De Brabanter, J. and De Cooman, L. 2012. Antioxidant potential of microalgae in relation to their phenolic and carotenoid content. Journal of Applied Phycology; 24(6): 1477-1486.

Gupta, S., Kapoor, P., Chaudhary, K., Gautam, A., Kumar, R., Raghava, G. P. 2013. In silico approach for predicting toxicity of peptides and proteins. PloS one; 8(9), e73957.

Hafting, J.T., Critchley, A.T., Cornish, M.L., Hubley, S.A. and Archibald, A.F. 2012. On-land cultivation of functional seaweed products for human usage. J Appl Phycol.; 24:385392.

Herrero, M., Cifuentes, A., Ibanez, E. 2006. Sub-and supercritical fluid extraction of functional ingredients from different natural sources: Plants, food-by-products, algae and microalgae: A review. Food chemistry; 98(1): 136-148.

$\mathrm{Li}$, H., Chen ,B. and Yao, S. 2005. Application of ultrasonic technique for extracting chlorogenic acid from Eucommia ulmodies Oliv. (E. ulmodies). Ultrasonics Sonochemistry; 12(4): 295-300. 
Sustainability, Agri, Food and Environmental Research, (ISSN: 0719-3726), 8(X), 2020:

http://dx.doi.org/10.7770/safer-VONO-art2252

Liyana-Pathirana, C. and Shahidi, F. 2005. Optimization of extraction of phenolic compounds from wheat using response surface methodology. Food Chemistry; 93(1): 47-56.

Mata, T. M., Martins, A.A. and Caetano, N.S. 2010. Microalgae for biodiesel production and other application: a review. Renewable and sustainable energy reviews; 14 (1) 217232.

Naczk, M. and Shahidi, F. 2004. Extraction and analysis of phenolics in food. Journal of Chormatography A; 1054 (1-2): 95-111.

Pan, G., Yu, G., Zhu, C. and Qiao, J. 2012. Optimization of ultrasound-assisted extraction (UAE) of flavonoids compounds (FC) from hawthorn seed (HS). Ultrason. Sonochem.; 19: 486490.

Rawson, A., Tiwari, B.K., Patras, A., Brunton, N., Brennan, C., Cullen, P.J. and O'Donnell, C. 2011. Effect of thermosonication on bioactive compounds in watermelon juice. Food Res. Int. 44: 1168-1173.

Saha, S.K., McHugh, E., Murray, P. and Walsh, D.J. 2016). Microalgae as a source of nutraceuticals. Phycotoxins: Chemistry and Biochemistry; 255-291.

Shalaby, E.A. and Shanab, S.M.M. 2013. Antiradical and antioxidant activities of different Spirulina platensis extracts against DPPH and ABTS radical assays. J Mar Biol Oceanography; 2:1-2.

Singleton, V.L. and Rossi, J.A. 1965. Colorimetry of total phenolics with phosphomolybdicphosphotungstic acid reagents. Am. J. Enol. Vitic. 16: 144-158.

Tabaraki, R., Nateghi, A. 2011. Optimization of ultrasonic-assisted extraction of natural antioxidants from rice bran using response surface methodology. Ultrasonics sonochemistry; $18(6)$ : 1279-1286.

Wang, H., Provan, G. J. and Helliwell, K. 2004. Determination of rosmarinic acid and caffeic acid in aromatic herbs by HPLC. Food Chemistry; 87(2), 307-311.

Wang, L. and Weller, C.L. 2006. Recent advances in extraction of neutraceuticals from plants. Trends Food Science Technology; 17: 300-312.

WHO, 2007. Protein and Amino Acid Requirements in Human Nutrition. Report of a Joint FAO/WHO/ UNU Expert Consultation, WHO Technical Report Series 935. World Health Organization, Geneva, Switzerland.

Received: 03th July 2020; Accepted: $30^{\text {th }}$ September 2020; First distribution: $17^{\text {th }}$ October 2020. 